\title{
Comparative Effects of Postharvest Ultraviolet-Light Treatments on Antioxidants Properties, Nutritional and Vitamin D Contents of Some Indigenous Green Leafy Vegetables
}

\author{
Tolulope Omotope Omolekan ${ }^{1} \quad$ Adewale Michael Esan ${ }^{2 *} \quad$ Charles Ojo Olaiya ${ }^{2}$ \\ Oluwasegun Joseph Anjorin ${ }^{2} \quad$ Kamarudeen Adewumi Aremu ${ }^{3}$ Henry Rinde Y. Adeyemi ${ }^{4}$ \\ 1.Biochemistry Department, Bowen University Iwo, Osun State, Nigeria \\ 2.Department of Biochemistry, Faculty of Basic Medical Sciences, University of Ibadan, Oyo State, Nigeria \\ 3.Department of Integrated Sciences, Kwara State College of Education, Oro, Kwara State, Nigeria \\ 4.Department of Biochemistry, Federal University of Technology Minna, Niger State, Nigeria
}

\begin{abstract}
Ultraviolet lamps irradiation has been extensively used in water treatment, surface disinfection, and as a germicidal agent. Yet, activation of some essential reactions in fruits and vegetables occurs at low doses of irradiation, which in turn leads to an improvement of their shelf-life or bioactive compounds. In this study, postharvest effects of ultraviolet irradiation at different wavelengths were investigated on antioxidants properties, nutritional and vitamin D contents of six leafy vegetables. The six vegetables were each subjected to UV-A, B, and C lamps irradiation at wavelengths of 400,315 , and $230 \mathrm{~nm}$ respectively in irradiation chambers. The results revealed that ultraviolet irradiation increased the phenolic and flavonoid contents with a better-reducing power ability and antioxidant capacity in tested vegetables. More also, the essential amino acid contents were significantly $(\mathrm{P} \leq 0.05)$ increased. In UV-A treatment, increased nutritional and antioxidant properties were significant $(\mathrm{P} \leq 0.05)$ in $M$. oleifera leaf extract. On the other hand, a significant $(\mathrm{P} \leq 0.05)$ increase in the level of vitamin D2 and D3 synthesis in the leaves of all the vegetables was observed under UV-B treatment. The results revealed that $M$. oleifera leaf responds more positively to ultraviolet irradiation than other treated vegetables. Therefore, this study shows that postharvest treatments with UV-A and B lamps may be a useful biological strategy for enhancing the antioxidant and nutritional quality of vegetables.
\end{abstract}

Keywords: Antioxidant activity, UV-radiation, Vegetables, Bioactive compounds, Vitamin D.

DOI: $10.7176 /$ ALST/88-04

Publication date:July $31^{\text {st }} 2021$

\section{Introduction}

Free radical's generation is not far-fetched in organisms' natural processes of metabolism. The endogenous antioxidant enzymes in an organism scavenge these free radicals. Any derangement in the antioxidant functions of an organism results to the accumulation of free radicals in the body, which causes damage to biomolecules and in turn brings about various diseases like cardiovascular disease, atherosclerosis, hormonal disorder, and other related diseases (Li et al. 2013). Kidney disease is one of the major life-threatening diseases that decrease the quality of life, and it is ranked the eighteenth highest cause of death worldwide in 2010 (Lozano et al. 2012). The most common causes of chronic kidney disease (CKD) in the developed world are diabetes mellitus and hypertension, whereas, in sub-Saharan Africa, the commonest causes are hypertension and chronic glomerulonephritis (Rashad \& Barsoum, 2006). The study confirms that high consumption of vegetables and fruits with health benefiting bioactive compounds reduces the incidence of diseases that constitute economic problems (Dyshlyuk et al. 2017). Hence, a potential source of natural antioxidants can be derived from plant products. The use of plants for ethnomedicine is fast gaining recognition and publicity in Africa and the rest of the world, because of their affordability and availability and they are relatively cheap (Choi et al. 2012). Vegetables have a large number of bioactive compounds such as saponin, lignans, terpenoids, and flavonoids (Oomah \& Mazza, 2000). It has been reported that vegetables have phytochemicals with similar activity as the synthetic chemicals recommended by USA NKF KDOQ/I (NKF, 2002). Oxalate in plants acts as calcium binders, phytate acts as phosphorus binder and vitamin $\mathrm{D}_{2}$ which has similar activity with synthetic calcitriol. More also, recent advances suggest that plants could also synthesize calcitriol (Japelt et al. 2011) which has better and more effective outcome than vitamin $\mathrm{D}_{2}$. Vitamin $\mathrm{D}_{3}$ have been identified in some plant species like Solanaceae, Cucurbitaceae, Fabaceae, and Poaceae (Skliar et al. 2000). This led to the estimation of vitamin D in plant matrixes: Amaranthus hybridus, Brassica oleracea, Hibiscus sabdariffa, Lactuca capensis, Solanum melongena, and Moringa oleifera, which are some of the important vegetables in Nigerian diets. However, it is noteworthy that the vitamin D contents in these vegetables are very low (Magalhaes et al. 2007). A method or strategy to improve this in vegetables will be of great value.

Recent development in the use of UV light irradiation has shown a considerable promise for the shelf-life extension in fruits and vegetables (Allende \& Artes, 2003). Also, UV-light irradiation helps in the postharvest 
treatment of fruits and vegetables, which has reported to reduce decay, delay senescence, increase antioxidant activity, and induce several phytochemicals (Lu et al. 2016). Irradiation with UV-C lamp has been known for flavones enhancement in grape berry skin (Crupi et al. 2013). Ultraviolet-C lamp irradiation increased flavonoid accumulation, which in turn contributes to free radical scavenging and improves the antioxidant activity in fruits and vegetables (Rivera-Pastrana et al. 2014). According to Zhou et al. (2007) who reported a molecular mechanism of flavonoids accumulation in plants treated with UV-A and B. However, in our literature search, there is a paucity of information regarding postharvest UV-A, B and $\mathrm{C}$ treatments effects on $A$. hybridus, B. oleracea, $H$. sabdariffa, L. capensis, S. melongena, and $M$. oleifera on vitamin D, antioxidants potential and nutritional contents. Therefore, the present study examined the postharvest effects of UV-A, B and C treatments on the antioxidants potential, nutritional and vitamin D contents of six leafy vegetables.

\section{Materials and Methods}

\subsection{Plant samples}

The fresh leaves of A. hybridus, B. oleracea, H. sabdariffa, L. capensis, M. oleifera, and S. melongena, were collected from the Bodija market, Ibadan, the authentication was done at the Department of Botany Herbarium, University of Ibadan, where the voucher numbers were deposited (UIH-21131, UIH-22213, UIH-21213, UIH22712, UIH-22913, UIH-22913 respectively). The perforated and damaged leaves were removed, the dust from the fresh leaves was cleaned with water and then air-dried. The selected vegetables were used for the experiment.

\subsection{Treatment with ultraviolet lamps}

The ultraviolet lamps were on for about $15 \mathrm{~min}$ for stabilization. The vegetable samples were irradiated with ultraviolet lamps A, B, and C in a rectangular box. Each sample received a UV radiation of 8watts lamps at a distance and dose of $70 \mathrm{~cm}$ and $2.217 \mathrm{~J} / \mathrm{m}^{2}$ respectively for $1 \mathrm{~h} /$ day/vegetable for one week at a room temperature as described by Japelt et al. (2011), while control was not irradiated. The ultraviolet lamps A, B, and C used were of wavelengths 400,315 , and $230 \mathrm{~nm}$ respectively.

\subsection{Plant preparation}

After the irradiation, the vegetables were lyophilized, milled using a warring blender (Ultra-Turrax T25, Staufen, Germany) and refrigerated at $-20^{\circ} \mathrm{C}$ respectively. About $30 \mathrm{~g}$ of each sample was soaked for $24 \mathrm{~h}$ in distilled water with intermittent shaken. The muslin cloth was used to filter the homogenate. A rotary evaporator was used to concentrate the filtrate at $40^{\circ} \mathrm{C}$ and stored for analysis.

\subsection{Assays for antioxidants}

\subsubsection{Sample's phenolic content determination}

The sample's total phenolic content was estimated by using the method of Kim et al. (2003). Briefly, $1 \mathrm{~mL}$ of the

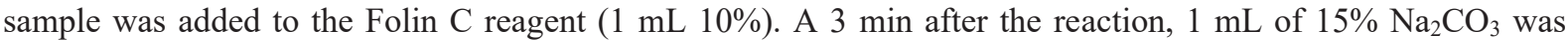
added and made up to the volume with distilled water. The resulting mixture was kept in the dark with intermittent shaken for $90 \mathrm{~min}$. The reading was taken at $760 \mathrm{~nm}$. The standard used was gallic. Phenolic content in the sample was expressed as $\mathrm{mg} \mathrm{GAE} / \mathrm{g}$.

\subsubsection{Sample's flavonoid content determination}

The sample's flavonoid content was estimated by using the method of Park et al. (2008). A $10 \mu \mathrm{g}$ of the extract was mixed with $\mathrm{NaNO}_{2}(75 \mu \mathrm{l}$ of $5 \%)$ in $1 \mathrm{ml}$ of distilled water. Also, followed by the addition of $\mathrm{AlCl}_{3} \cdot 6 \mathrm{H}_{2} \mathrm{O}$ $(150 \mu \mathrm{l}$ of $10 \%), \mathrm{NaOH}(500 \mu \mathrm{l}$ of $1 \mathrm{M})$ and distilled water $(275 \mu \mathrm{l})$ after $5 \mathrm{~min}$. The reading was taken at 510 $\mathrm{nm}$. The standard used was Quercetin. Flavonoid content in the sample was expressed as mg QUE/g.

\subsubsection{Reducing power ability}

The reducing power ability of the samples was determined by the method of Oyaizu (1986). Briefly, $10 \mu \mathrm{g} / \mathrm{mL}$ of the extract in distilled water was suspended into sterile test tubes. A phosphate buffer $(2.5 \mathrm{~mL})$ and $\mathrm{K} 3$ $\left[\mathrm{Fe}(\mathrm{CN})_{6}\right](2.5 \mathrm{~mL})$ was dispensed into each of these test tubes. The mixture was incubated for $20 \mathrm{~min}$ at $50^{\circ} \mathrm{C}$. Thereafter, $10 \% \mathrm{w} / \mathrm{v}, 1.5 \mathrm{~mL}$ TCA was added to stop the reaction. The mixture was subjected to centrifugation at $3000 \mathrm{~g}$ for $10 \mathrm{~min}$. The aliquot $(2.5 \mathrm{~mL})$ was added to $0.5 \mathrm{~mL}$ of $0.1 \% \mathrm{FeCl}_{3}$. The reading was taken at $700 \mathrm{~nm}$. The standard used was a Catechin.

\subsubsection{Sample's radical scavenging activity (DPPH) determination}

The method of Yen \& Chen (1995) was used to estimate the DPPH radical scavenging activity of the samples. A sample extract $(40 \mu \mathrm{g})$ was added to $1 \mathrm{~mL}$ of DPPH solution in $4 \mathrm{ml}$ of distilled water. The resulting mixture was vortex and kept for $30 \mathrm{~min}$ at $25^{\circ} \mathrm{C}$. The reading was taken at $517 \mathrm{~nm}$. The standard treated like the extract used was catechin. The DPPH percentage inhibition was determined as follows:

$\%$ DPPH scavenging ability $=\frac{A \text { bs control-Abs sample }}{\text { Abs control }} \times 100$ 


\subsubsection{Sample's hydroxyl radical scavenging activity determination}

The hydroxyl radical scavenging activity of the samples was determined by the method of Halliwell et al. (1987). Briefly, $1 \mathrm{mM}$ of EDTA, $\mathrm{FeCl}_{3}$, ascorbic acid, $\mathrm{H}_{2} \mathrm{O}_{2}$ respectively and $28 \mathrm{mM}$ deoxyribose were prepared in distilled water. A $0.33 \mathrm{~mL}$ of phosphate buffer $(50 \mathrm{mM}, \mathrm{pH} 7.4)$ and $0.1 \mathrm{~mL}$ of $11 \mathrm{mM}$ ascorbic acid were added to $1.0 \mathrm{~mL}$ of plant extract. The mixture was incubated for $1 \mathrm{~h}$ at $25^{\circ} \mathrm{C}$. The addition of $1.0 \mathrm{~mL}$ of $10 \%$ TCA and $1.0 \mathrm{~mL}$ of $0.5 \%$ TBA resulted in the development of the pink chromogen and the absorbance is taken at $532 \mathrm{~nm}$. Ascorbic acid was used as the standard. The percentage of hydroxyl radical scavenging activity was calculated as follows:

Calculation

$\%$ Hydroxyl radical scavenging activity $=\frac{\text { Abs control-Abs sample }}{A b s \text { control }} \times 100$

\subsubsection{Metal chelating ability}

The metal chelating ability of the samples was determined by the method of Dinis et al. (1994). The reading was taken at $560 \mathrm{~nm}$.

$\%$ Metal chelating ability $=\frac{\text { Abs control-Abs sample }}{\text { Abs control }} \times 100$

\subsection{Determination of samples oxalate content}

The oxalate content of the samples was determined by the method of Day \& Underwood (1986). A $150 \mathrm{~mL}$ of $15 \mathrm{~N} \mathrm{H}_{2} \mathrm{SO}_{4}$ was added to $5 \mathrm{~g}$ of the sample, and the mixture was vortex carefully for $30 \mathrm{~min}$ and filtered by Whatman No 1 filter paper. A $25 \mathrm{~mL}$ of the filtrate was collected and titrated against $0.1 \mathrm{~N} \mathrm{KMNO}_{4}$ solution until a persistent faint pink colour appeared for $30 \mathrm{sec}$. The titre value was calculated to get the concentration of oxalate in the vegetable materials.

\subsection{Determination of samples phytate content}

The method of Reddy and Salunkhe (1980) was followed to determine the phytate content of the samples. A 50 $\mathrm{mL}$ of $3 \%$ trichloroacetic acid (TCA) was used to extract $1 \mathrm{~g}$ of the sample for 30 min with intermittent shaken and then centrifuged for $30 \mathrm{~min}$ at 5,800 g. The aliquot that contains phytic acid was precipitated with $4 \mathrm{~mL}$ $\mathrm{FeCl} 3$ solution containing $0.2 \% \mathrm{FeCl}_{3}$ in $3 \%$ TCA. The precipitated ferric phytate was converted to $\mathrm{Fe}(\mathrm{OH})_{3}$ with $3 \mathrm{~mL}$ of $1.5 \mathrm{~N} \mathrm{NaOH}$ after series of washing, heating, centrifuging and decanting of the precipitate (Wheeler \& Ferrel, 1971). A $40 \mathrm{~mL}$ of hot $3.2 \mathrm{~N} \mathrm{HNO}^{-3}$ was used to dissolve $\mathrm{Fe}(\mathrm{OH})_{3}$ and the iron was estimated colourimetrically using 1.5 M KCN. The reading was taken at $480 \mathrm{~nm}$ against a reagent blank for each set of sample. From $\mathrm{Fe}\left(\mathrm{NO}_{3}\right)_{3}$ standard curve, the iron content was determined. The phytic acid content was estimated from the atomic ratio of iron to phosphorus (4:6) (Okon \& Akpanyung, 2005).

\subsection{Calcium content determination}

The calcium content of the samples was determined by the method of AOAC (1990). A $2 \mathrm{~g}$ of each sample was heated in a crucible and ignited in a muffle furnace for $6 \mathrm{~h}$ at $550^{\circ} \mathrm{C}$ to obtain ash content. The desiccator was used to cool the mixture and then weighed at room temperature to get the constant weight of the ash. The ash obtained was digested in a crucible with the addition of $5 \mathrm{~mL}$ of $2 \mathrm{M} \mathrm{HCl}$ and heat to dryness on a heating mantle. Another addition of $5 \mathrm{~mL}$ of $2 \mathrm{M} \mathrm{HCl}$ was added, boiled and filtered by a Whatman No. 1 filter paper into a volumetric flask. Distilled water was added to the filtrate to make up the mark. Calcium concentration was read using the Flame photometer (PFP7 model). The concentration of the calcium was calculated using the formula.

$\%$ Calcium $=\frac{\text { Meter reading } \times \text { slope } \times \text { Dilution factor }}{1000} \times 100$

\subsection{Phosphorus content determination}

A spectrophotometric method of AOAC (1990) was employed to estimate the phosphorus content of the samples. The ash was obtained as described above for calcium. The filtrate $(10 \mathrm{~mL})$ was pipette into a $50 \mathrm{ml}$ standard flask and immediately followed by the addition of vanadate-molybdate $(10 \mathrm{~mL})$ solution. The flask was made up to the mark with distilled water, and stand for $10 \mathrm{~min}$ for the development of yellow colour. The reading was taken at $470 \mathrm{~nm}$.

$\%$ Phosphorus $=\frac{\text { Absorbance } \times \text { slope } \times \text { Dilution factor }}{1000} \times 100$ 
2.9. Determination of 7-hydrocholesterol, ergosterol vitamin $D_{3}$ and $D_{2}$

The 7-dehydrocholesterol, vitamin $\mathrm{D}_{2}$, and $\mathrm{D}_{3}$ contents in the selected vegetables were estimated by using the HPLC method of Japelt et al. (2011).

\subsection{Statistical analysis}

The Statistical Product and Service Solution software (Version 20) was used to analyze the data. Results were expressed as a mean \pm SD. The level of significance was determined using a two-way ANOVA followed by an LSD test at $\mathrm{P} \leq 0.05$.

\section{Results}

\subsection{Flavonoid and phenolic contents}

Figures 1 and 2 show the flavonoid and phenolic contents results in the treated and untreated vegetables. UV irradiation increased vegetables'flavonoid and phenolic contents, but a significant $(\mathrm{P} \leq 0.05)$ increase in flavonoid and phenolic contents were found in M. oleifera and A. hybidus treated with UV-A and B respectively, as compared to the control and other groups.

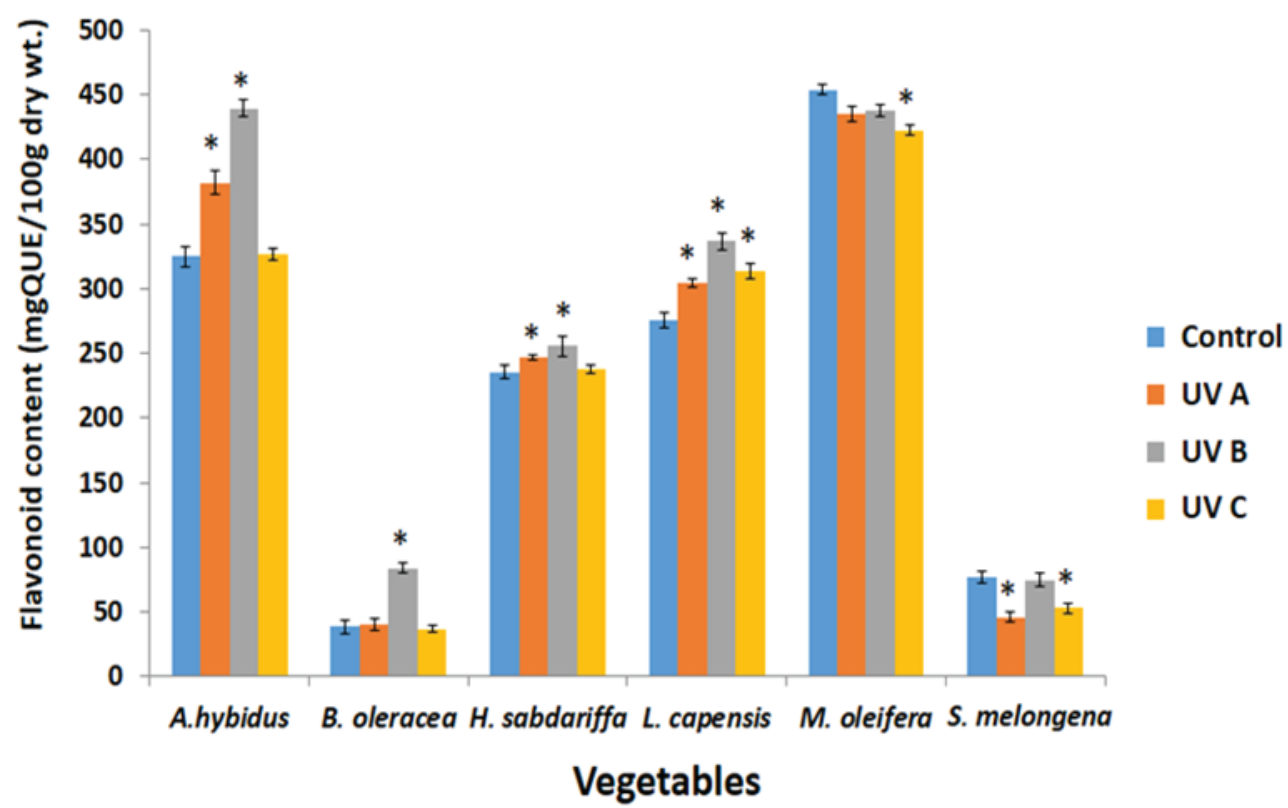

Figure 1. Postharvest effects of ultraviolet irradiation on total flavonoid content in the selected vegetables Mean \pm SD $(n=3)$ was used for the data expression. *Significant $(\mathrm{P} \leq 0.05)$ difference from the control groups.

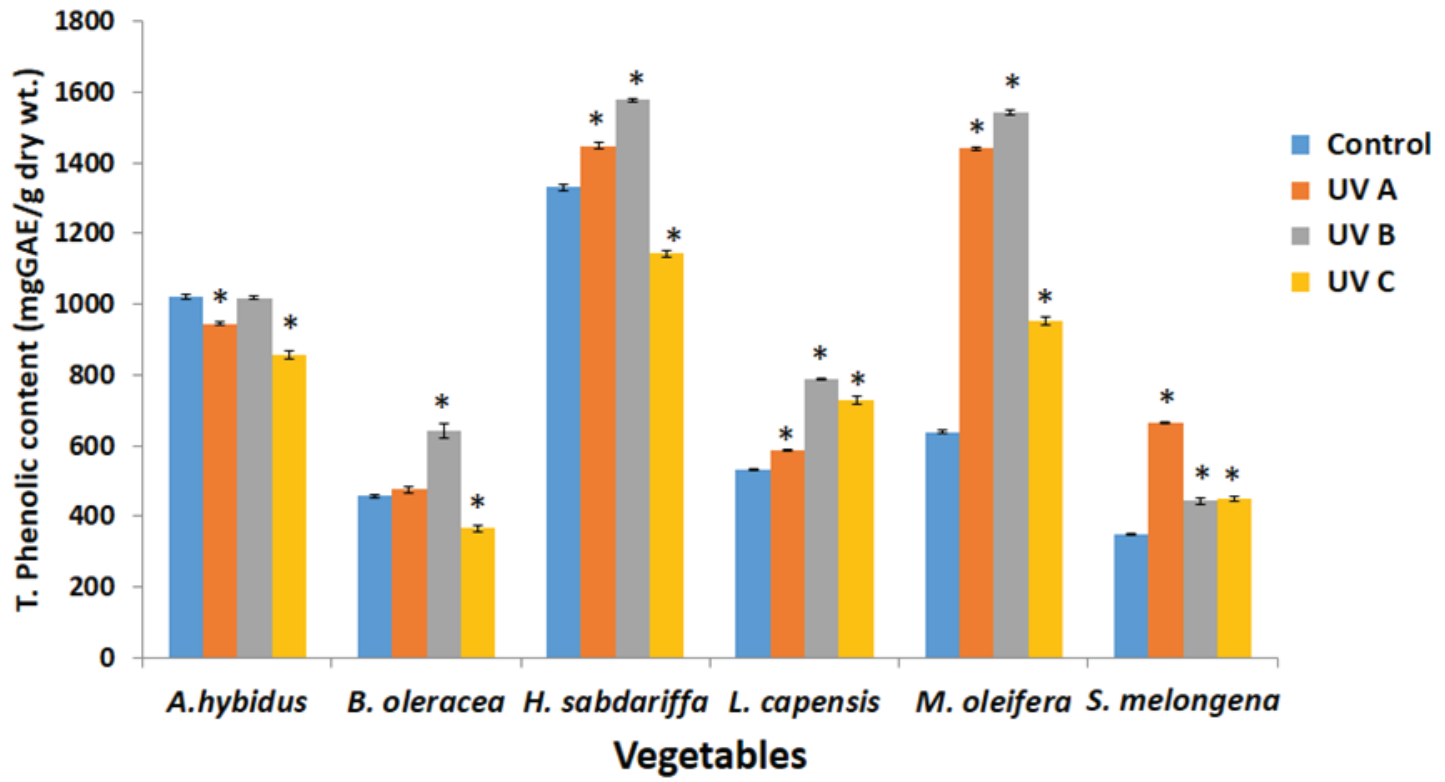

Figure 2. Postharvest effects of ultraviolet irradiation on total phenolic content in the selected vegetables Mean \pm SD $(n=3)$ was used for the data expression. *Significant $(\mathrm{P} \leq 0.05)$ difference from the control groups. 


\subsection{Reducing power ability}

The reducing power ability of vegetable leaves extracts is shown in Figure 3. Only the extracts of M. oleifera and $S$. incanum showed higher reducing power abilities in all treatments as compared to the control group. However, little or no noticeable effect of ultraviolet irradiation (A, B and C) was found on reducing power ability of other extracts when compared with the control groups.

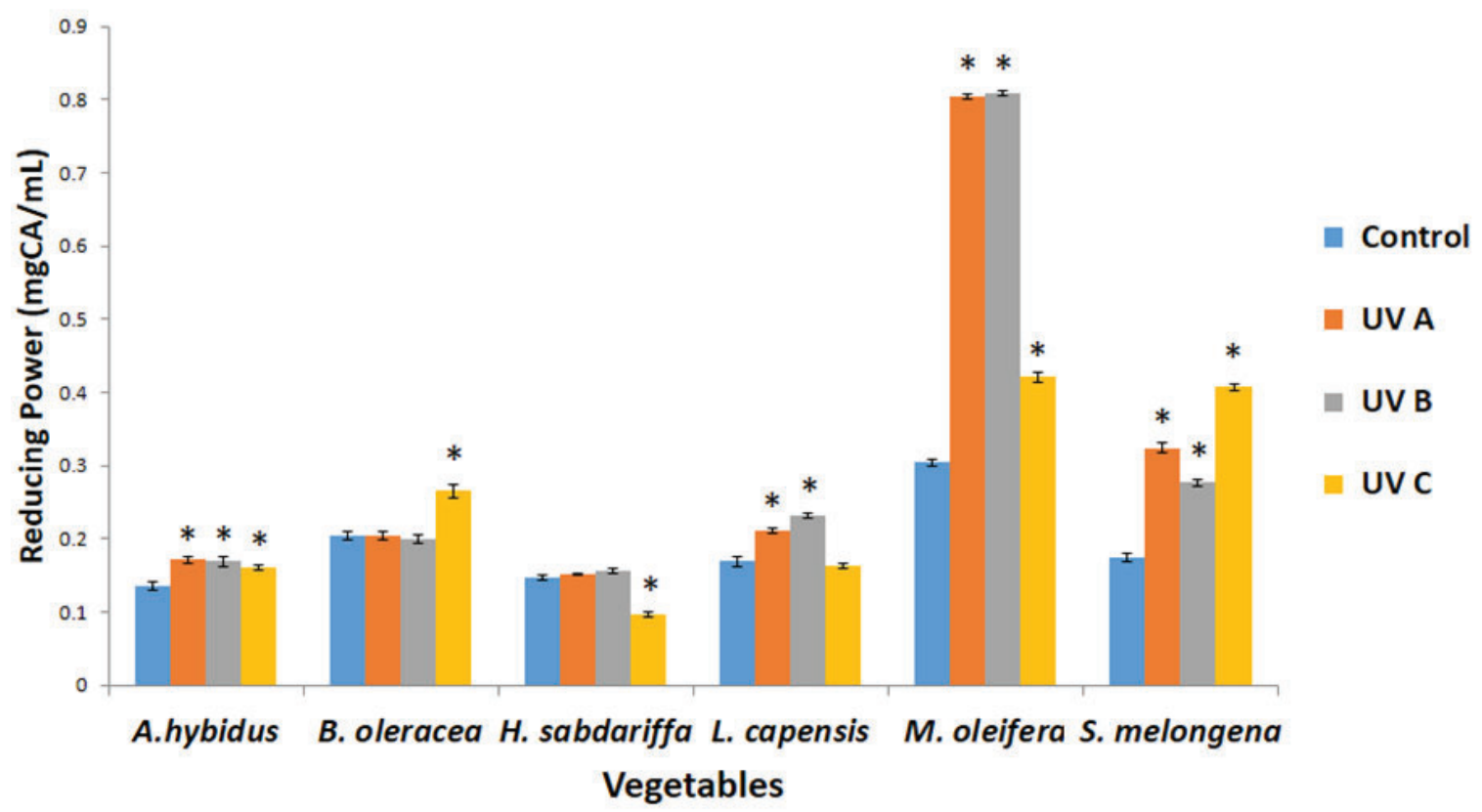

Figure 3. Postharvest effects of ultraviolet irradiation on reducing power capability in the selected vegetables. Mean $\pm \operatorname{SD}(n=3)$ was used for the data expression. *Significant $(\mathrm{P} \leq 0.05)$ difference from the control groups.

\subsection{DPPH radical and Hydroxyl scavenging activities}

The DPPH radical and hydroxyl scavenging percentage inhibition of the selected vegetables are shown in Figures 4 and 5. The UV-A, B and C treated M. oleifera showed higher percentage inhibition of hydroxyl radical activity when compared with the control and other groups (Fig. 5). However, no significant effect of the treatments (UV-A, B and C) was found on DPPH radical scavenging activity in treated vegetables when compared with the control groups (Fig. 4).

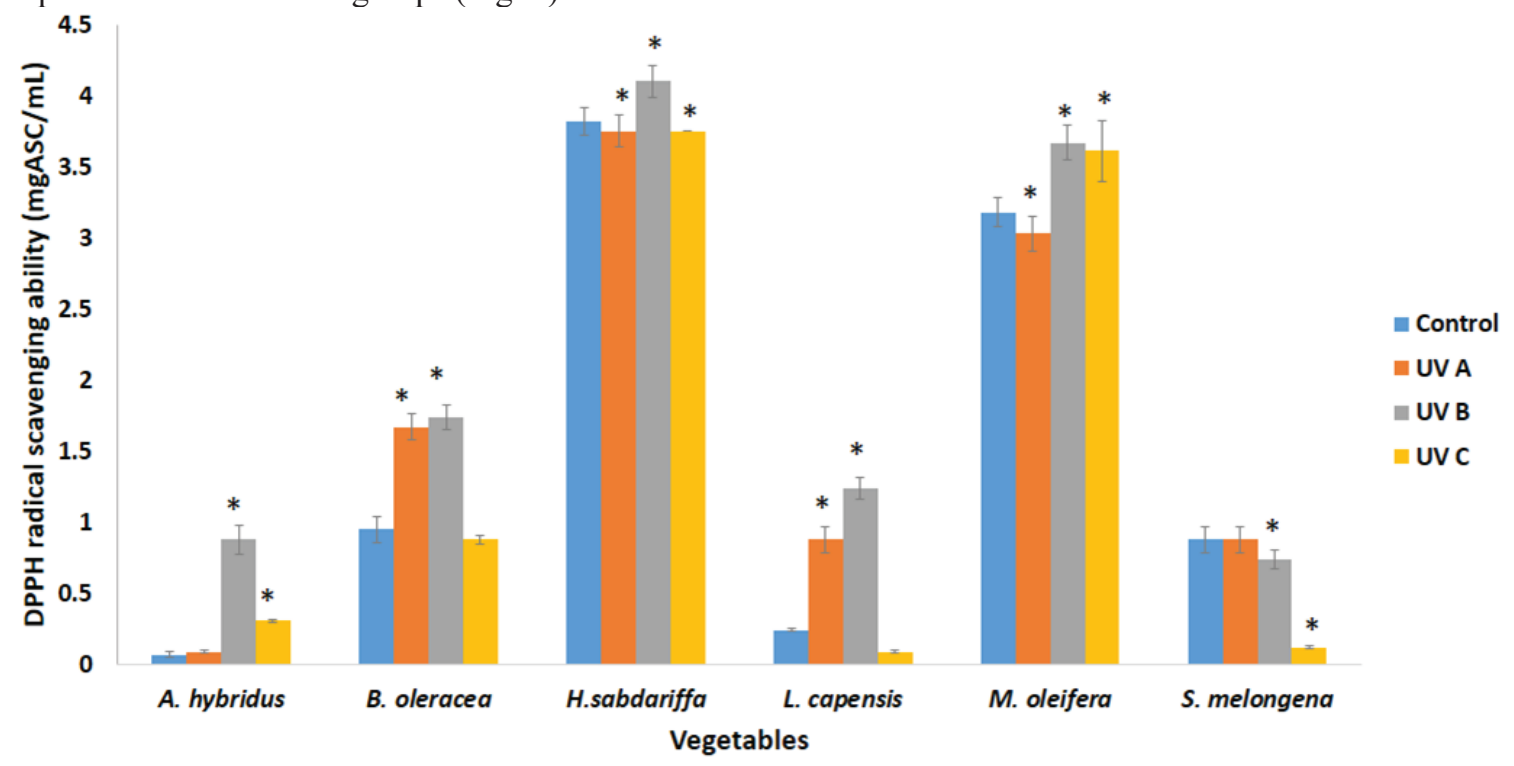

Figure 4. Postharvest effects of ultraviolet irradiation on percentage DPPH radical scavenging ability of the selected vegetables. Mean \pm SD $(n=3)$ was used for the data expression. *Significant $(P \leq 0.05)$ difference from the control groups. 


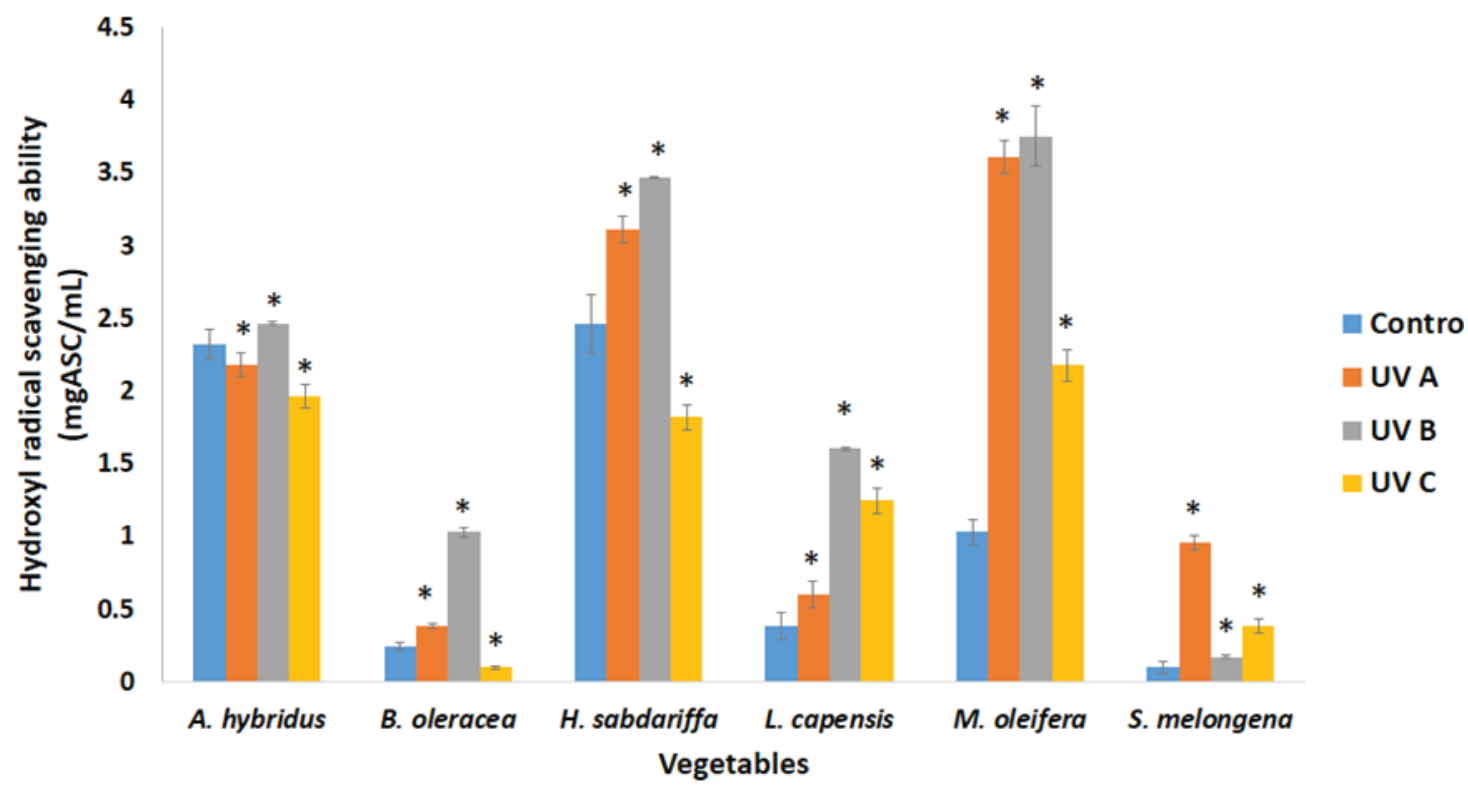

Figure 5. Postharvest effects of ultraviolet irradiation on percentage hydroxyl radical scavenging activity in the selected vegetables. Mean $\pm \mathrm{SD}(\mathrm{n}=3)$ was used for the data expression. *Significant $(\mathrm{P} \leq 0.05)$ difference from the control groups.

\subsection{Metal $\left(\mathrm{Fe}^{2+}\right)$ chelating ability}

The vegetable leaves extract metal chelating ability was determined, and the result was presented. Figure 6 shows that $A$. hybidus extract treated with UV-A and B has a higher metal chelating ability relative to the control group. The other extracts showed little or no effect on metal chelating ability under ultraviolet irradiation as compared to the control groups.

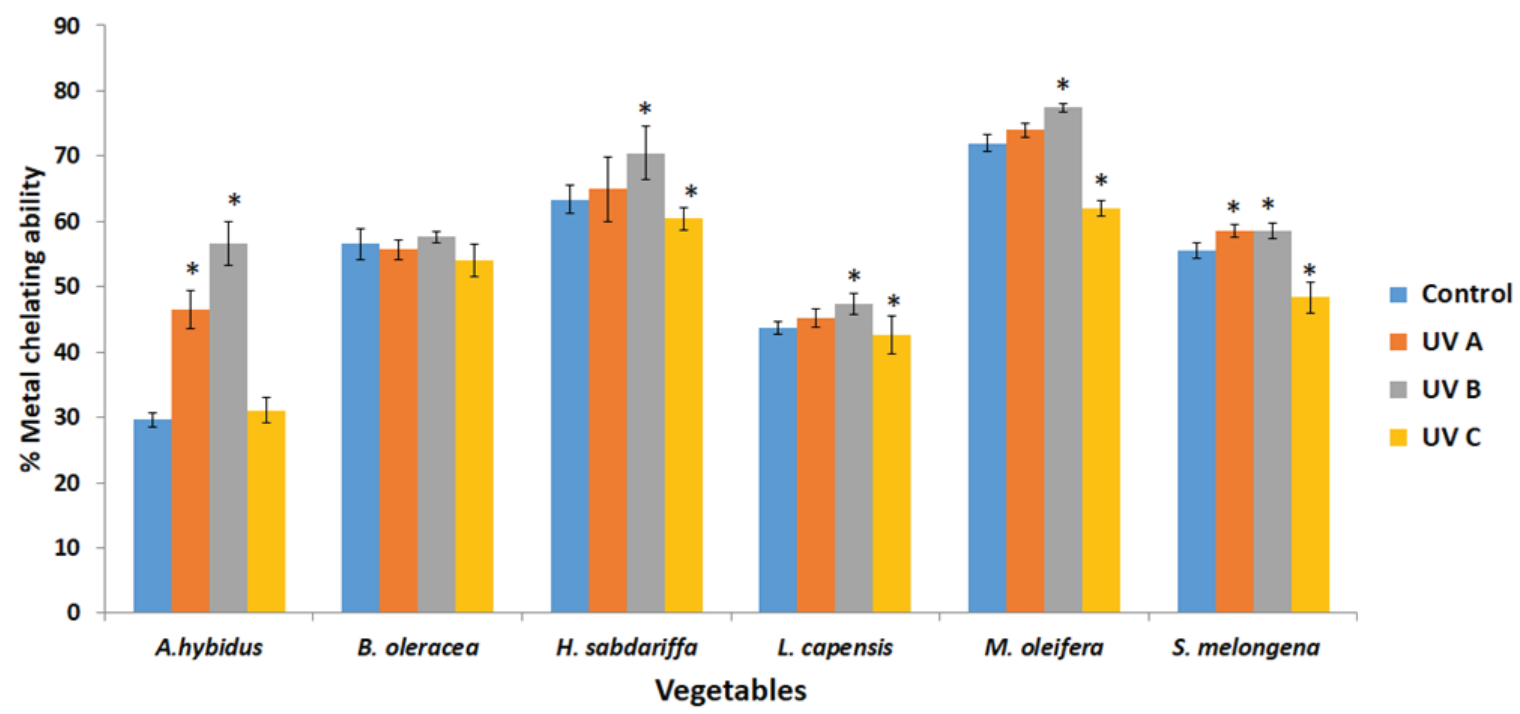

Figure 6. Postharvest effects of ultraviolet irradiation on percentage metal chelating ability in the selected vegetables. Mean $\pm \mathrm{SD}(\mathrm{n}=3)$ was used for the data expression. *Significant $(\mathrm{P} \leq 0.05)$ difference from the control groups.

\subsection{Anti-nutrients content}

As shown in Table 1, UV-A, B and C irradiation significantly $(\mathrm{P} \leq 0.05)$ reduced the oxalate content of the treated vegetables compare to their controls. On the other hand, the UV irradiation increased the vegetables'phytate content significantly $(\mathrm{P} \leq 0.05)$ except in $S$. melongena. 


\subsection{Minerals content}

The results show that ultraviolet irradiation treated and untreated vegetable leaves extracts exhibited the same calcium and phosphorus contents as compared to the control and other groups. However, H. sabdariffa, B. oleracea, L. capensis and M. oleifera had higher calcium content (Table 1).

Table 1. Postharvest effects of ultraviolet light treatments on oxalate, phytate, calcium and phosphorus contents in the selected vegetables

\begin{tabular}{|c|c|c|c|c|c|}
\hline Treated Veg. & $\mathbf{U V}$ & $\mathrm{Ca}(\%)$ & P (\%) & $\begin{array}{l}\text { Oxalate } \\
\text { dwt) }\end{array}$ & $\begin{array}{c}\text { (mg/g Phytate } \\
\text { dwt) }\end{array}$ \\
\hline \multirow[t]{4}{*}{ A. hybridus } & Control & $7.35 \pm 0.21$ & $22.81 \pm 0.01$ & $0.81 \pm 0.04$ & $2.47 \pm 0.02$ \\
\hline & A & $8.45 \pm 0.49$ & $23.80 \pm 0.14$ & $0.63 \pm 0.01 *$ & $2.88 \pm 0.04 *$ \\
\hline & B & $6.96 \pm 0.03$ & $22.82 \pm 0.03$ & $0.49 \pm 0.02^{*}$ & $3.09 \pm 0.01 *$ \\
\hline & $\mathrm{C}$ & $7.41 \pm 0.01$ & $22.80 \pm 0.14$ & $0.54 \pm 0.02 *$ & $2.88 \pm 0.04 *$ \\
\hline \multirow[t]{4}{*}{ B.oleracea } & Control & $211.80 \pm 0.31$ & $48.80 \pm 0.14$ & $0.59 \pm 0.04$ & $2.88 \pm 0.04$ \\
\hline & A & $212.90 \pm 0.14$ & $47.81 \pm 0.13$ & $0.45 \pm 0.01 *$ & $2.68 \pm 0.04 *$ \\
\hline & B & $210.80 \pm 0.11$ & $48.74 \pm 0.72$ & $0.49 \pm 0.02 *$ & $2.06 \pm 0.01 *$ \\
\hline & $\mathrm{C}$ & $214.90 \pm 0.13$ & $47.16 \pm 0.13$ & $0.48 \pm 0.01^{*}$ & $2.67 \pm 0.04^{*}$ \\
\hline \multirow[t]{6}{*}{ H. sabdariffa } & Control & $210.70 \pm 0.17$ & $48.70 \pm 0.22$ & $1.13 \pm 0.02$ & $2.47 \pm 0.02$ \\
\hline & A & $211.18 \pm 0.16$ & $47.80 \pm 0.13$ & $0.36 \pm 0.01 *$ & $2.47 \pm 0.02$ \\
\hline & B & $208.60 \pm 0.12$ & $48.81 \pm 0.33$ & $0.72 \pm 0.02 *$ & $2.88 \pm 0.04^{*}$ \\
\hline & $\mathrm{C}$ & $219.02 \pm 0.22$ & $48.70 \pm 0.12$ & $0.57 \pm 0.01^{*}$ & $2.88 \pm 0.04 *$ \\
\hline & Control & $224.60 \pm 0.22$ & $50.17 \pm 0.15$ & $0.61 \pm 0.01$ & $1.47 \pm 0.02$ \\
\hline & A & $220.10 \pm 0.13$ & $50.25 \pm 0.35$ & $0.43 \pm 0.01 *$ & $1.81 \pm 0.04 *$ \\
\hline \multirow{2}{*}{ L. capensis } & B & $224.70 \pm 0.12$ & $50.80 \pm 0.11$ & $0.49 \pm 0.02 *$ & $2.09 \pm 0.01 *$ \\
\hline & $\mathrm{C}$ & $219.10 \pm 0.11$ & $50.84 \pm 0.11$ & $0.44 \pm 0.02 *$ & $1.88 \pm 0.04 *$ \\
\hline \multirow{4}{*}{ M. oleifera } & Control & $216.58 \pm 0.23$ & $49.55 \pm 0.14$ & $2.68 \pm 0.03$ & $2.06 \pm 0.01$ \\
\hline & $\mathrm{A}$ & $218.81 \pm 0.21$ & $47.80 \pm 0.11$ & $1.08 \pm 0.01 *$ & $2.71 \pm 0.08^{*}$ \\
\hline & B & $220.65 \pm 0.11$ & $47.80 \pm 0.21$ & $1.61 \pm 0.02 *$ & $2.27 \pm 0.06^{*}$ \\
\hline & $\mathrm{C}$ & $218.67 \pm 0.12$ & $48.55 \pm 0.22$ & $1.62 \pm 0.02 *$ & $2.09 \pm 0.01 *$ \\
\hline \multirow{4}{*}{ S. melongena } & Control & $5.55 \pm 0.11$ & $24.80 \pm 0.15$ & $0.59 \pm 0.01$ & $1.75 \pm 0.01$ \\
\hline & A & $5.90 \pm 0.22$ & $25.60 \pm 0.41$ & $0.36 \pm 0.02 *$ & $1.75 \pm 0.01$ \\
\hline & B & $5.80 \pm 0.14$ & $24.77 \pm 0.16$ & $0.36 \pm 0.01 *$ & $1.75 \pm 0.01$ \\
\hline & $\mathrm{C}$ & $5.56 \pm 0.22$ & $25.75 \pm 0.11$ & $0.49 \pm 0.02 *$ & $1.75 \pm 0.01$ \\
\hline
\end{tabular}

Mean $\pm \mathrm{SD}(\mathrm{n}=3)$ was used for the data expression. *Significant $(\mathrm{P} \leq 0.05)$ difference from the control groups

\subsection{Ergosterol, 7-dehydrocholesterol (DCH), Vitamin $D_{2}$, and $D_{3}$ contents}

The results of the ergosterol, 7-dehydrocholesterol, vitamin $\mathrm{D}_{2}$, and $\mathrm{D}_{3}$, contents in treated vegetables were presented in Figure 7(a, b, c and d). The results show that the ergosterol and 7-DCH concentration in the UV-B treated vegetables significantly reduced relative to the control group. The concentration of 7 DCH in UV-A and $\mathrm{C}$ treated vegetables was reduced when compared with the control but not consistent across the treated vegetables (Fig. 7a). However, a consistent reduction was observed for ergosterol (Fig. 7c) The vitamin $\mathrm{D}_{3}$ concentration of UV-B treated vegetables was significantly $(\mathrm{P} \leq 0.05)$ increased as compared to the control groups. The concentration of vitamin $\mathrm{D}_{3}$ in UV-A and $\mathrm{C}$ treated vegetables showed no statistically significant difference from the control across the treated vegetables (Fig. 7b). The vitamin $\mathrm{D}_{2}$ concentration was significantly $(\mathrm{P} \leq 0.05)$ increased in UV-B treated vegetables relative to the control groups. However, no statistically significant increase in vitamin $\mathrm{D}_{2}$ concentration in UV-A and $\mathrm{C}$ treated vegetables relative to the control groups (Figure 7d). 


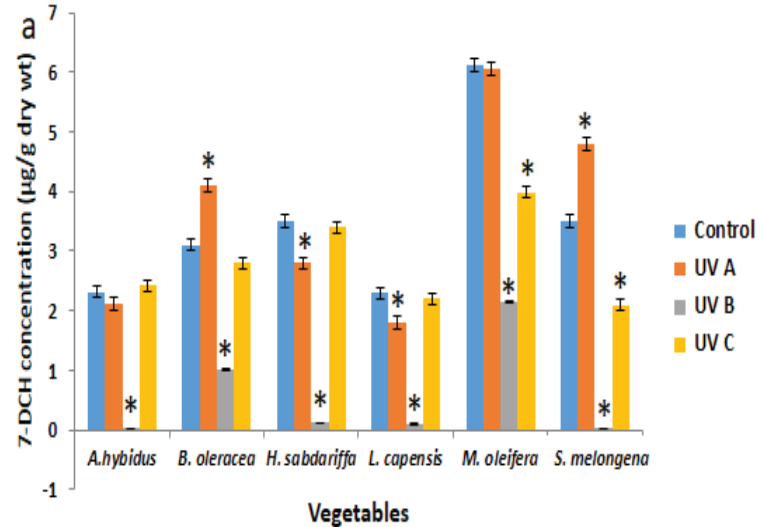

Vegetables

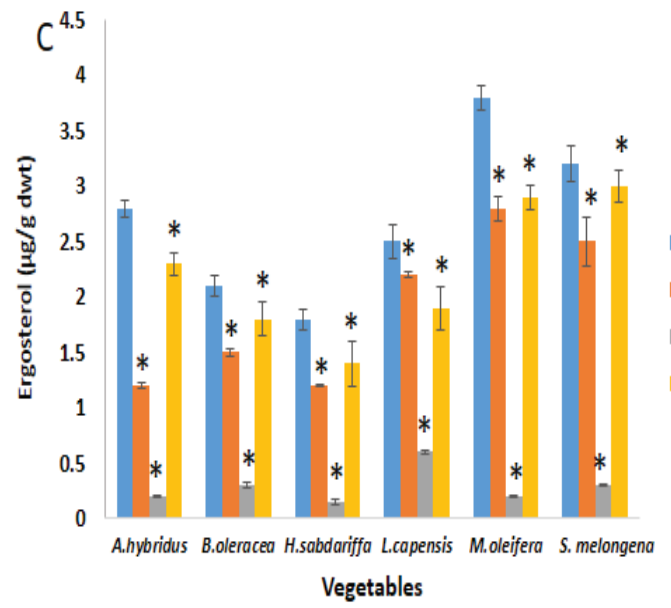

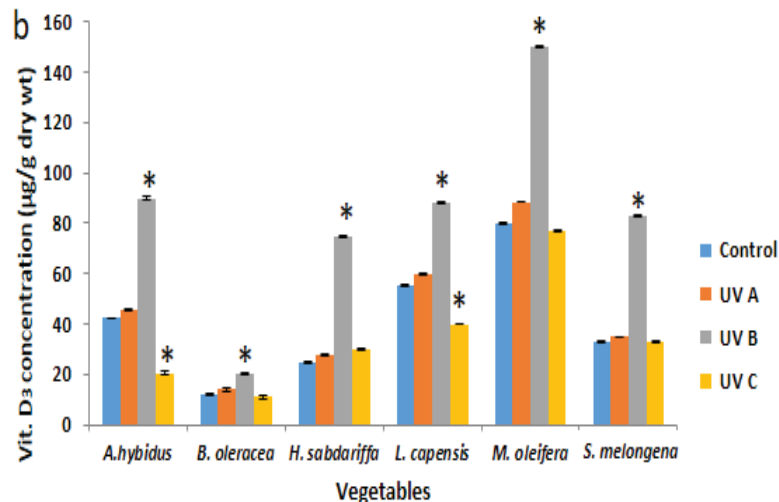

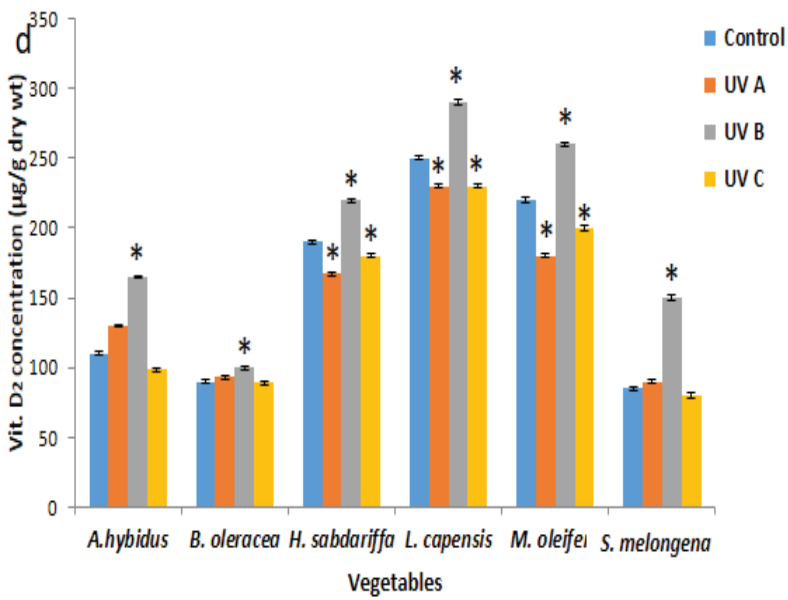

Figure 7 ( $a, b, c$ and d). Postharvest effects of ultraviolet irradiation on 7DCH, ergosterol, vitamin $\mathrm{D}_{3}$ and $\mathrm{D}_{2}$ contents of the selected vegetables. Mean $\pm \mathrm{SD}(\mathrm{n}=3)$ was used for the data expression. *Significant $(\mathrm{P} \leq 0.05)$ difference from the control groups.

\section{Discussion}

Ultraviolet irradiation serves as an alternative biological strategy that helps fruits and vegetables to increase their shelf-life through varying mechanisms (Shama, 2007). In response to UV irradiation, plants trigger their defense and anti-oxidative mechanism (Yun-Hee et al. 2007). It also serves as a germicidal agent, which readily alters the microbe's DNA and in turn affects cell division (Civello et al. 2006). In this work, we examined the postharvest ultraviolet lamps irradiation effects on antioxidants properties, nutritional and vitamin D contents of six leafy vegetables. The increased phenolic and flavonoid contents observed in M. oleiferaand A. hybidus when treated with UV-A and B respectively might be a result of the phenylalanine ammonia-lyase activation, which is responsible for the synthesis of bioactive compounds (phenolic and flavonoid) in plants tissues (Papoutsis et al. 2016). Furthermore, the higher scavenging potential of M. oleifera, A. hybidus, and S. incanum observed under UV-ultraviolet lamps irradiation treatments in this study suggest that they are possible antioxidant sources. In this regard, the M. oleifera and S. incanum extracts reducing power was estimated by reducing iron III to iron II, while the higher reducing power was exhibited in $M$. oleifera leaf extract compared to $S$. incanum leaf extract (Fig. 3). According to the report of Islam (2013), who observed a correlation between the plant's extracts antioxidants and their capacity to reduce oxidative stress. This could also be linked to the $M$. oleifera leaf extract rich phenolic content. The metal chelating ability of $A$. hybidus under UV-A and B treatments observed (Fig. 6) under this study is in tandem with the result of Finefrock et al. (2003) who observed the metal chelating ability of plants with high antioxidant potentials.

In this study, there were decreased oxalate content in M. oleifera leaf extract under UV-A and B treatments and increased phytate content in UV-A, B and C treated A. hybidus (Table 1). Also, M. oleifera leaf treated with UV-A, B and C exhibited higher contents of calcium and phosphorus which are important minerals for bone mineralization. Ultraviolet light irradiated plant material and inert food have been shown to possess anti-rickety properties (Raghuramulu, 1996). Ultraviolet $\mathrm{B}(302 \mathrm{~nm})$ enhances the synthesis of Vitamin $\mathrm{D}_{2}$ and $\mathrm{D}_{3}$ in irradiated vegetables. This follows the report that vitamin $\mathrm{D}_{3}$ and $\mathrm{D}_{2}$ are synthesized by the action of UV-B at 
$302 \mathrm{~nm}$ wavelength on the diene at the carbon 5 and 7 of the 7 dehydrocholesterol (Japelt et al. 2011; Mello, 2003). In addition, increased vitamin $\mathrm{D}_{3}$ content in the vegetables with concomitant decreased 7dehydrocholesterol after UV B treatment showed that 7-dehydrocholesterol is the precursor of vitamin $\mathrm{D}_{3}$ in the irradiated vegetables and also that the photolytic pathway for its synthesis exists in the irradiated vegetables. This is also applicable to ergosterol and vitamin $\mathrm{D}_{3}$ in the treated vegetables.

\section{Conclusion}

Medicinally and traditionally, vegetables are considered as the major sources of nutrients and antioxidants. In this study, after ultraviolet irradiation-A, B and C, all the treated vegetables still maintained many of their antioxidant capacity and physicochemical properties. The ultraviolet irradiation induced the synthesis of phenolic and flavonoid with a better-reducing power ability and antioxidant capacity in the tested vegetables. Conclusively, our results indicate that postharvest UV-A treatments significantly increased the nutritional and antioxidant properties of $M$. oleifera leaf extract, and UV-B treatment exhibited a significant increase in vitamin $\mathrm{D}_{2}$ and $\mathrm{D}_{3}$ levels in the leaves of all the vegetables. Enhancement of vitamin $\mathrm{D}$ in vegetables could be a useful dietary intervention for the management of vitamin D insufficiency and the reversal of kidney damage in patients. In this regard, $M$. oleifera leaf extract tends to be the most promising among all investigated vegetables, and thus need to be subjected to further study. Therefore, the UV-A and B treatments may be a useful biological strategy for enhancing the antioxidant and physicochemical postharvest quality of vegetables.

\section{Conflicts of interest}

No competing interest exists among the authors.

\section{References}

Allende, A. \& Artes, F. (2003). "UV radiation as a novel technique to preserve the quality of minimally processed 'Lollo Rosso' lettuce', Food Res. Int. 36, 739-746.

AOAC (1990) Official methods of analysis. (15th edition), Association of Official Analytical Chemist, Washington DC

Choi H.J., Kim E.J., Shin Y.W., Park J.H., Kim D., \& Kim J.K., (2012), "Protective Effect of Heat - processed Ginseng (Sun Ginseng) in the Adenine-induced Renal Failure rats”, J Ginseng Res 36 (3), 270 - 276.

Civello, P., Vicente, A., \& Martinez, G. (2006), "UV-C technology to control postharvest of fruit and vegetables," in Recent Advances in Alternative Postharvest Technologies to Control Fungal Diseases in Fruits and Vegetables, R. Troncoso-Rojas, M. E. Tiznado-Hernandez, A. Gonzalez-Leon, and R. TroncosoRojas, Eds., Trans world Research Network, Kerala, India.

Crupi, P., Pichierri, A., Basile, T. \& Antonacci, D. (2013) 'Postharvest stilbenes and flavonoids enrichment of table grape cv Redglobe (VitisviniferaL.) as affected by interactive UV-C exposure and storage conditions", Food Chem. 141, 802-808.

Day, R.A. \& Underwood, A.L. (1986), ‘Quantitative analysis 5th ed. Prentice. Hall publication'” P. 701.

Dinis, T.P.C., Madeira, V.M.C. \& Almeida, L.M. (1994), 'The action of phenolic derivatives (acetaminophen, salicylate and 5-aminosalicylate) as inhibitors of membrane lipid peroxidation and as peroxy radical scavengers", Arch. Biochem. Biophy. 315, 161-169.

Dyshlyuk, L., Babich, O., Prosekov, A., Ivanova, S., Pavsky, V. \& Yang, Y. (2017), ''In vivo study of medical and biological properties of functional bakery products with the addition of pumpkin flour', Bioact. Carbohydr. Diet. Fib. 12, 20-24.

Finefrock, A.E., Bush, A.I. \& Doraiswamy, P.M. (2003), "Current status of metals as therapeutic targets in Alzheimer's disease', J. Am. Ger. Soc. 51, 1143-1148.

Islam, M.M. (2013), 'Biochemistry, medicinal and food values of jute (Corchoruscapsularis L. and C. olitorius L.) leaf: a review', Int. J. Enhanc. Res. Sci. Technol. Eng. 2, 135-144.

Jäpelt, R.B., Silvestro, D., Smedsgaard, J., Jensen, P.E. \& Jakobsen, J. (2011), 'LC-MS/MS with atmospheric pressure chemical ionization to study the effect of UV treatment on the formation of vitamin D3 and sterols in plants", Food Chem. 129, 217-225.

Kim, D.O., Chun, O.K., Kim, Y.J., Moon, H.Y. \& Lee, C.Y. (2003) ''Quantification of polyphenolics and their antioxidant capacity in fresh plums", J. Agricult. Food. Chem. 516, 509-6515.

Li, H., Horke, S. \& Forstermann, U. (2013) 'Oxidative stress in vascular disease and its pharmacological prevention', Trends Pharmacol. Sci. 34(6), 313-319.

Lozano R, Naghavi M, \& Foreman K. (2012), 'Global and regional mortality from 235 causes of death for 20 age groups in 1990 and 2010: a systematic analysis for the Global Burden of Disease Study" Lancet 380, 2095-128.

Lu,Y., Zhang,J., Wang, X., Lin, Q., Liu, W., Xie, X., Wang, Z. \& Guan, W. (2016), ''Effects of UV-C irradiation on the physiological and antioxidant responses of button mushrooms (Agaricusbisporus) during 
storage', Int. J. Food Sci. Tech. 51, 1502-1508.

Magalhães P.J., Carvalho D.O., Guido L.F., \& Barros A.A. (2007), “Detection and quantification of provitamin D2 and vitamin D2 in the hop (Humulus lupulus L.) by liquid chromatography-diode array detectionelectrospray ionization tandem mass spectrometry', J. Agric. Food Chem. 55, 7995-8002.

Mello, J. R. B. (2003), “Calcinosis-calcinogenic plants”, Toxicon, 41(1), 1-12.

National kidney foundation. K/DOQI (2002). clinical practice guidelines for chronic kidney disease: Evaluation, Classification and Stratification. Am J. Kidney Dis 39: S1-S266.

Okon, E.U. \& Akpanyung, E.O. (2005), 'Nutrients and anti-nutrients in selected brands of malt drinks produced in Nigeria", Pakistan, Journal of Nutrition 4 (5), 352-355.

Oomah, B.D. \& Mazza, G. (2000), “Functional Foods. In: Francis, F.J. (Ed.). The Wiley Encyclopedia of Science and Technology”, vol. 2, second ed., Wiley, New York, NY. pp. 1176-1182.

Papoutsis, K., Quan, V., Pristijono, V.P., Golding, J.B., Bowyer, M.C., Scarlett, C.J. \& Stathopoulos, C.E. (2016), 'Enhancing the total phenolic content and antioxidants of lemon pomace aqueous extracts by applying UV-C irradiation to the dried powder', Foods 5 (55), 1-10.

Prema T. P. \& Raghuramulu. N. (1996), "Vitamin D3 and its metabolites in Tomato Plant. Phytochemistry', 42 (3): $617-620$

Rashad S. \& Barsoum, M.D. (2006), "Chronic Kidney Disease I in the Developing World". New England Journal of Medicine 354, 997-999.

Reddy N.R. \& Salunkhe D.K. (1980), ''Effects of Fermentation on Phytate phosphorus andminerals content in black grain, rice and black grain and rice blends', J. Food Sci 45, $1708-1712$.

Rivera-Pastrana, D. M., Gardea, A. A., Yahia, E. M., Martinez-Tellez, M. A. \& Gonzalez-Aguilar, G. A. (2014), "Effect of UV-C irradiation and low-temperature storage on bioactive compounds, antioxidant enzymes and radical scavenging activity of papaya fruit', J. Food Sci. Tech. 51, 3821-3829.

Shama, G. (2007), "Process challenges in applying low doses of ultraviolet light to fresh for eliciting beneficial hormetic responses," Postharvest Biology and Technology, 44(1), 1-8.

Skliar, M., Curino, A., Milanesi, L., Benassati, S. \& Boland, R. (2000), 'Nicotianaglauca: another plant species containing vitamin $\mathrm{D}_{3}$ metabolite', Plant Sci. 156, 193-199.

Wheeler E.L. \& Ferrel R.E. (1971), "A method for phytic acid determination in wheat and wheat fraction" cereal. Chem. 48, 312-320.

Yen, G. C. \& Chen, H. Y. (1995), "Antioxidant activity of various tea extracts in relation to their antimutagenicity." Journal of Agriculture. Food Chemistry., 43, 27-37.

Yun-Hee, K., Soon L., Sim-Hee H., Jae-Cheon L., Wan-Keun S., Jae-Wook B., Suk-Yoon K., Haeng-Soon L. \& Sang-Soo K. (2007) 'Differential expression of 10 sweet potato peroxidase in response to dioxide, ozone, and ultraviolet radiation', Plant Physiology and Biochemistry, 45, 908 - 914.

Zhou, B., Li, Y., Xu, Z., Yan, H., Homma, S. \& Kawabata, S. (2007), “Ultraviolet A-specific induction of anthocyanin biosynthesis in the swollen hypocotyls of turnip (Brassica rapa)', J. Exp. Bot. 58, 1771- 1781. 